\title{
EDITORIAL
}

\section{Editorial Procedures for the Monthly Weather Review}

Starting with this issue, the editorship of the Monthly WEATHER REVIEW is transferred to a new team. Under this new stewardship we will continue the previous editorial policy which has permitted the publication of an outstanding professional journal. Since changing from NOAA to AMS sponsorship, the MoNTHLy WEATHER REVIEW has prospered and grown under, first, the editorship of Chester W. Newton and, recently, Donald R. Johnson and his editors, John J. Cahir, James C. Fankhauser and John B. Hovermale. We will continue their policy of strict and rigorous review of submitted scientific manuscripts.

The new Chief Editor is Roger A. Pielke, Associate Professor of Environmental Sciences at the University of Virginia. The three Editors are Lance F. Bosart, Associate Professor of Atmospheric Sciences at the State University of New York at Albany, J. Michael Fritsch, Research Meteorologist at the Environmental Research Laboratories in Boulder, Colorado, and Paul E. Long, Research Meteorologist at the Techniques Development Laboratory of the National Weather Service.

The objectives of the Monthly Weather Review are briefly discussed on the inside front cover of this issue. A more detailed discussion of the subject areas that are appropriate for publication in MWR and other AMS journals is described in the August 1975 issue of the BULLETIN (p. 785).

All new manuscripts submitted for publication to MWR will be sent to the Chief Editor, who will assign each manuscript to one of the Editors, including himself. The broad areas of responsibility for the Editors include:

- Lance F. Bosart-aspects of synoptic modeling and conventional weather forecasting, including forecast validation and other applications of statistical techniques.

- J. Michael Fritsch-mesoscale analysis and forecasting, certain aspects of model parameterization and severe weather.

- Paul E. Long-all scales of modeling studies, including those of the planetary boundary layer, as well as papers dealing with solution techniques.

Each editor designated for a paper has the responsibility and authority for securing appropriate reviews, corresponding directly with the author, and determining the editorial decision regarding its publication. As a matter of policy, comments from authors will be accepted only in writing.

In regard to the review process, our staff will follow the editorial policies established by the Publications Commission of AMS. "An Author's Guide to the Journals of the American Meteorological Society", prepared by the Publications Commission under the direction of Peter $V$. Hobbs, will be utilized in implementing this policy. It is anticipated that the Guide will be published by the end of the year.

With the continued assistance of the reviewers within the scientific community and of the technical support from AMS Headquarters in Boston, we trust that the MonTHLY Weather REVIEW will continue to be an outstanding professional journal.

Roger A. Pielke 